\title{
Bursting balloons - comparison of risk taking between extreme sports, esports, and the general public
}

\author{
Lucas Keller $^{1}$ (D) $\cdot$ Maik Bieleke $^{2}$ (D) $\cdot$ Wanja Wolff ${ }^{2}$ (D)
}

Accepted: 7 December 2021

(c) The Author(s) 2021

\begin{abstract}
Arguably, extreme sports athletes exhibit a more significant risk appetite than the general public. Are standard behavioral risk measures able to capture this? To answer this question, we assessed self-reports of risk taking and measured the risk-taking behavior of samples of snowboarders and climbers. Two groups of non-athletes, university students and crowdworkers, and athletes of a sport that does not include the potential of grave injury or death, esports athletes, serve as control conditions and complement our study. Across these five different groups, 1313 participants performed an online version of the Balloon Analogue Risk Task (BART) and gave self-reports of general willingness to take risks and sports-specific risk taking. Extreme sports athletes exhibited greater risk taking in the BART than non-athletes and esports athletes. Furthermore, BART-performance predicted sports-specific risk taking and its affective consequences. Our results speak to the BART's ecological validity and the unique role of physical consequences on risk-taking behavior.
\end{abstract}

Keywords Risk taking $\cdot$ Extreme sports $\cdot$ Esports

Taking risks is an essential part of life. It is often necessary to advance, push boundaries, or succeed. Not surprisingly, individuals' propensities to take risks have attracted attention as a crucial determinant of behavior and have long been in researchers' interest in psychology and adjacent fields. Perhaps nowhere else is this ubiquity of risk taking more apparent than in sports, exemplified by famous quotes like "you miss $100 \%$ of the shots you don't take" by hockey's great Wayne Gretzky. However, various sports differ drastically in the risks athletes can take and the potential consequences that loom. In virtually every sport, taking risks - like playing very aggressively in a video game - can have adverse psychological

\footnotetext{
All authors developed the study concept and oversaw survey creation. All authors designed the study. Lucas Keller analyzed the data. All authors interpreted the data. Lucas Keller drafted the manuscript, and all authors provided critical revisions. All authors approved the final version of the manuscript for submission.
}

Lucas Keller

lucas.keller@uni-konstanz.de

1 Department of Psychology, University of Konstanz, Universitätsstr. 10, 78464 Konstanz, Germany

2 Department of Sport Science, University of Konstanz, Konstanz, Germany consequences when it is failing (e.g., shame, regret, embarrassment; e.g., Carver \& Scheier, 1990; Zeelenberg, 1999). Some other sports also involve risks with potential bodily harm, like going for a grab trick after a botched takeoff in snowboarding, risking potential injuries, or participating in other extreme sports where errors can have fatal consequences (Cohen et al., 2018).

It is unclear whether athletes who risk physical harm in their sports differ in their risk appetite from the general public or athletes whose sports involve similar training schedules but not such physical consequences. In examining risk taking, self-reports and behavioral measures of risk taking usually make different contributions (Frey et al., 2017). Consequently, in this article, we compare extreme sports athletes (climbers, snowboarders) with esports athletes (competitive video game players; Pedraza-Ramirez et al., 2020) and the general public (students, crowdworkers) using one of the most popular behavioral risk-elicitation tasks, the Balloon Analogue Risk Task (BART; Lejuez et al., 2002), along with self-reports of general and sports-specific risk taking. We investigate to which degree sports-specific risk appetite can be captured by the BART beyond self-reports. 


\section{(Self-Reports of) Risk Taking in Sports}

If probed for their primary motivation to engage in extreme sports, most athletes state the positive experiences elicited by the activity and not the thrill of the inherent risk of injury or death (e.g., Brymer, 2010; Brymer \& Mackenzie, 2017). Hanoch et al. (2006) observed that, on average, extreme sports athletes do not evince increased risk taking in non-sport domains like investing or gambling. For instance, taking the physical risk of BASE jumping is seen as a mere means to the end of experiencing something extraordinary (Allman et al., 2009). Because precautions are taken, extreme sports athletes report being in control and low perceived risk concerning their extreme activity's potential adverse outcomes (see also Baretta et al., 2017).

Conversely, other questionnaire research has shown that athletes, in general, do exhibit more risky behaviors than non-athletes. Wetherill and Fromme (2007) observed that college-bound high school athletes report greater alcohol use, more sexual partners, and lower perceived risk of negative consequences of their behavior than non-athletes. Similarly, differences between sports have been observed; for instance, Schneider and Greenberg (1992) observed that tennis players exert less risky behaviors than other athletes. Further, athletes of high-risk sports score higher on measures of risk taking than athletes of low-risk sports (Steinbrink et al., 2020) and show higher levels of sensation seeking (i.e., the inclination to search for novel and complex experiences; Crust, 2020). The elevated levels of sensation seeking of high-risk sports participants have even been likened to individuals with opioid addiction (Franques et al., 2003). Simultaneously, however, Barlow et al. (2013) argue that agency (i.e., the experience of acting in a certain, autonomous way), not sensation seeking, drives athletes. In sum, these findings seemingly contradict each other as athletes exert more risky behaviors but are not necessarily more risk taking in self-report measures.

\section{The Special Case of Esports}

In contrast to extreme sports, esports does not pose immediate risks to physical wellbeing. Research on risk taking among gamers is sparse. Asking undergraduates to play video games for 30 minutes, Buelow et al. (2015) observed an increase in some executive functions but no increase in risk-taking behavior in the BART. Other researchers observed an association between a history of playing reckless-driving or other risk-glorifying games and risky driving (e.g., Fischer et al., 2007; Stollberg \& Lange, 2020) or risky behaviors such as smoking, aggression, or delinquency (e.g., Hull et al., 2014), respectively. However, some of these findings are disputed (see Hilgard et al., 2019; Drummond et al., 2021). Furthermore, they refer more to leisure/casual than competitive gaming and correlations with specific risky behaviors than general risk taking or risk appetite.

In competitive gaming, taking risks promises high rewards; esports today is a high-stakes, multi-million-dollar sport (Gough, 2021). Recent tournaments featured prize pools of up to $\$ 35,000,000$, making the five winning team members each earning more than the Wimbledon Championships winner. Compared to this heavyweight market status, psychological research has been relatively late to catch up (e.g., Pedraza-Ramirez et al., 2020). The sports-related risk taking in esports does not include immediate physical consequences; thus, it remains open whether esports athletes differ in their risk appetite from the general public or athletes in sports involving physical risk.

\section{Toward a Better Understanding of Risk Taking in Sports}

Taken together, previous research has focused on sportsrelated differences in self-reported risk taking and provided a largely inconsistent picture. Further, when asked to gauge their general willingness to take risks, it heavily depends on which domain extreme sports athletes have on their minds (Hanoch et al., 2006). In contrast, behavioral risk-taking measures benefit from eliciting risk taking in a more or less natural environment (Steiner \& Frey, 2021) independent of beliefs about domain-specific risk taking. One of the most prominent behavioral measures of risk taking, the Balloon Analogue Risk Task (BART), has been used across various experimental settings (e.g., brain research, Sehrig et al., 2021; lab studies, Lauriola et al., 2014), with different groups of participants (e.g., adolescents, Aklin et al., 2005; older adults, Rolison et al., 2012), and to investigate diverse research questions.

The BART is sensitive to situational differences in risk appetite and predicts various risk-related behaviors. It helped gather evidence for research questions addressing whether wearing a bicycle helmet may increase risk-taking behavior (Gamble \& Walker, 2016) or whether people before and after deciding in favor of a goal differ in their risk appetite (Keller \& Gollwitzer, 2017). In addition, adolescents' BART-performances predicted their real-world risk-taking behaviors (Lejuez et al., 2003), maternal BART-performance predicted their offsprings' alcohol use escalation (Banducci et al., 2015), and inner-city drug users were classified more accurately when taking their BART scores into account (Hopko et al., 2006), attesting to its construct validity (see also Hunt et al., 2005). 
Table 1 Sample Characteristics Concerning Risk Appetite, Relative to Climbers and Snowboarders

\begin{tabular}{llllll}
\hline & \multicolumn{4}{l}{ Sample characteristic (hypothesized association with risk taking) } \\
\cline { 2 - 6 } & $\begin{array}{l}\text { Athletes } \\
(\mathrm{R} \pi)\end{array}$ & $\begin{array}{l}\text { Physical risks } \\
(\mathrm{R} \pi)\end{array}$ & $\begin{array}{l}\text { Age } \\
(\mathrm{R})\end{array}$ & $\begin{array}{l}\text { Gender } \\
(\text { オ }=\mathrm{R} \pi)\end{array}$ & $\begin{array}{l}\text { Incentives } \\
(\mathrm{R} \pi)\end{array}$ \\
\hline Climbers \& Snowboarders & $\sqrt{ }$ & $\sqrt{ }$ & & & $\times$ \\
Gamers & $\sqrt{ }$ & $\times$ & younger & more & $\times$ \\
University students & $\times$ & $\times$ & younger & more + & $\sqrt{ }$ \\
Crowdworkers & $\times$ & $\times$ & older & more + & $\times$ \\
\hline
\end{tabular}

Note. $\mathrm{R} \pi$ resembles risk-increasing variables, $\mathrm{R} \$ resembles risk-decreasing variables. Younger, older, more $\hat{\sigma}$, and more $q$ is meant relatively to Climbers and Snowboarders.

\section{The Present Study}

Little is clear about the risk appetite of extreme sports athletes compared to esports athletes and the general public, partly because of undue reliance on self-report measures in the literature. Here, we capitalize on the BART, a valid measure of actual risk-taking behavior that circumvents some of the shortcomings of self-reported risk taking. We hypothesize that behavior in the BART is related to realworld risk taking, demonstrating a higher level of risk taking in extreme sports athletes due to their habitual enduring of potential physical consequences compared to non-athletes or athletes in a sport lacking such consequences (i.e., esports).

To this end, we collected data from five different groups of respondents. First, we recruited two groups of extreme sports athletes, climbers and snowboarders (Cohen et al., 2018), and hypothesized them to be the most risk seeking because they voluntarily engage in a sport where risk taking can result in injuries or even death. The other groups' inclusions were carefully designed to provide a robust test of this hypothesis as their risk appetite should vary based on sample characteristics (see Table 1). More specifically, groups varied across gender, age, and whether they were incentivized or not. Previous research could show that men are more willing to take risks than women (e.g., Charness \& Gneezy, 2012) and that older individuals are more risk averse than younger individuals (e.g., Dohmen et al., 2011). Lastly, we assume that incentivizing performance in the BART will, if anything, increase risk taking (e.g., as assumed in Lejuez et al., 2002). However, it has to be noted that the role of incentives in risk taking is not entirely clear (e.g., BrañasGarza et al., 2021; Camerer \& Hogarth, 1999). For instance, Brañas-Garza and colleagues have found no meaningful difference between incentivized and non-incentivized versions of measures of risk-taking preferences.

Compared to snowboarders and climbers, esports athletes were hypothesized to be the most similar to extreme sports, as esports evinces many parallels (e.g., similar training schedules, frequent sports-related risk taking). Increasing potential risk taking when compared to extreme sports athletes, gamers were younger, and the sample comprised more men, both factors known to promote risk taking. However, crucial to our hypothesis, their sport does not involve taking physical risks, which we assume will lead to decreased risk taking compared to extreme sports athletes. Students, our second control sample, were incentivized and relatively young (both factors known to promote risk taking), constituting a particularly rigorous control group, while the sample of crowdworkers comprised more women, and participants were comparatively older. Both factors are known to decrease risk taking, which is why we assumed them to be the most risk averse.

Picking up the hypothesized difference in risk appetite between non-athletes, esports, and extreme sports athletes was the focus of this investigation. We further included sports-specific risk assessments and, for extreme sports athletes, a scenario to test whether the BART can also predict sports-specific risk preferences. Importantly, all athletes had extended experience in their respective sports (e.g., on average five years for gamers, 15 years for snowboarders), reported a substantial weekly training load (e.g., on average for about 318 minutes per week for climbers), and at least a quarter in each sport were actively participating in competitions at various levels (up to international level). Thus, our athlete samples can be considered true experts for their respective sports.

\section{Method}

Materials, data, and analysis scripts can be found online at https://researchbox.org/202.

\section{Design, Participants, and Sample Size Considerations}

We collected data from five different groups (climbers, snowboarders, gamers, university students, crowdworkers). While differing in specifics, Qualtrics was used to run all surveys, and all participants completed the study online. All participants performed the same implementation of the BART. For the present investigation, we classified responses 


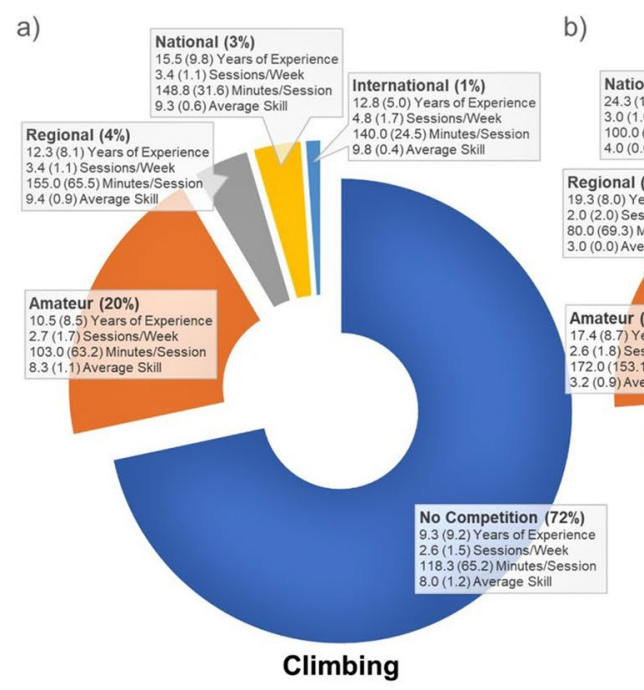

b)

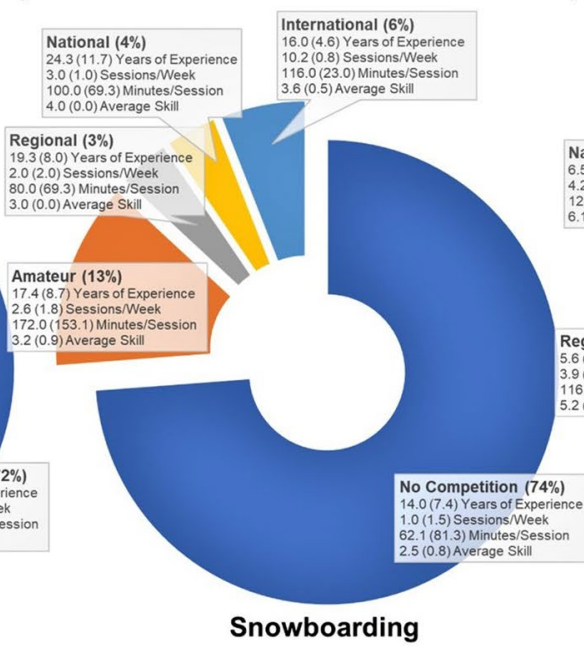

c)

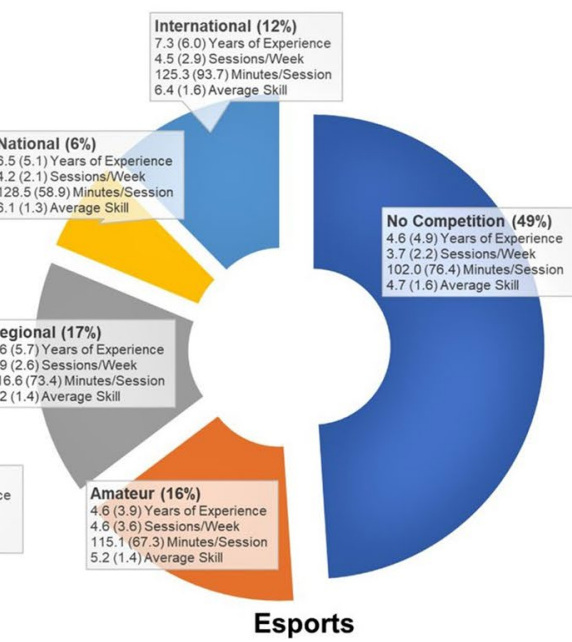

Fig. 1 Means (Standard Deviations) for Experience, Training, and Skill as a Function of Group and Competition Level

as started when participants gave their informed consent and as eligible for data analyses when they performed the BART and answered at least the question that assesses the general willingness to take risks (GWR, their stated risk preference; Dohmen et al., 2007), even when they did not finish the whole survey. Moreover, three climbers and one gamer let all 20 balloons burst, resulting in an undefined average number of pumps. Sample sizes for different analyses may vary because of that. Groups varied markedly in their gender composition from $95 \%$ male gamers to $74 \%$ female students and in size from 84 snowboarders to 533 gamers. Nevertheless, the collected sample sizes allow for the reliable test (80\% power) of correlations larger or equal to $r=.296$ in case of the smallest group (snowboarders) and down to correlations larger or equal to $r=.121$ and $r=.077$ in case of the largest group (gamers) and all participants, respectively (Faul et al., 2007). Similarly, the sample size allowed for the reliable test of group differences of larger or equal to $d=0.19$ or $\eta_{p}^{2}=.009$ in ANOVAs with all participants. Regarding the multiple regression analyses, the minimum required increases in $R^{2}$ for a predictor to be detected were $.006, .008$, and .018 for the whole sample, all athletes, and only extreme sports athletes, respectively.

\section{Active Climbers}

Climbers were recruited via various online forums, climbing gyms, and (inter)national climbing federations. Of 570 climbers who began the survey, 353 (62\%) were eligible for data analysis. Participants were between 18 and 67 years old $(M=31.6, S D=10.6)$ and predominantly male (83\%, one respondent indicated other). Climbers indicated on average 9.9 years of climbing experience $(S D=9.1)$ as well as that they train on average 2.7 times per week $(S D=1.5)$ and 118.3 minutes per session $(S D=64.3)$. They indicated their level of expertise on the 12-point Union Internationale des Associations d'Alpinisme-Scale by an average of $8.2(S D=1.2)$. Translations from other scales (Yosemite Decimal Systems or French Scale) were provided to ensure accurate self-descriptions. Furthermore, $28 \%$ indicated participating in competitive climbing. Fig. 1a provides a breakdown of the average experience, training, and skill across competition levels.

\section{Active Snowboarders}

Snowboarders were recruited via various online forums and with the help of national snowboarding federations. Of 120 snowboarders who began the survey, $84(70 \%)$ were eligible for data analysis. Participants were between 18 and 62 years old $(M=29.7, S D=8.4)$ and predominantly male (79\%). Snowboarders indicated on average 15.1 years of snowboarding experience $(S D=7.8)$ as well as that they train on average 1.9 times per week $(S D=2.7)$ and 83.2 minutes per session $(S D=97.8)$. Furthermore, $26 \%$ indicated participating in competitive snowboarding. They indicated their level of expertise as one of four categories that were described in detail ranging from Beginner (6\%) to Advanced (37\%) to Skilled (35\%) to Expert (23\%), $M=2.7$, $S D=0.9$. Figure $1 \mathrm{~b}$ provides a breakdown of the average experience, training, and skill across competition levels.

\section{Active Gamers}

Gamers were recruited via various online forums. Of 1288 gamers who began the survey, 533 (41\%) were eligible for 
data analysis. Of those who dropped out, only one participant dropped out after starting the BART (in this case, directly after the first balloon). Participants were between 18 and 66 years old $(M=24.5, S D=6.3)$ and predominantly male (95\%, eight respondents indicated other). During the survey, gamers could decide on one of 71 popular multiplayer online games or list their own choice as the main game of interest and indicated on average 5.2 years $(S D=$ 5.1 ) of playing this game (series). They also indicated that they train on average 4.2 times per week $(S D=3.6)$ and 118.3 minutes per session $(S D=184.9)$ for that game. They indicated their level of expertise on a 9 point Likert-scale ranging from Beginner to Master on average as $5.2(S D=$ 1.6). Furthermore, $51 \%$ indicated participating in gaming competitions. Figure 1c provides a breakdown of the average experience, training, and skill across competition levels.

\section{University Students}

University students were recruited from the local subject pool of a German university. Of 202 students who began the survey, 170 (84\%) were eligible for data analysis. Participants were between 18 and 55 years old $(M=24.1, S D$ $=5.4$ ) and predominantly female (74\%). Participants in this group also constitute the sample of a publication investigating an unrelated research question (Keller et al., 2021).

\section{Crowdworkers}

Crowdworkers were recruited from CloudResearch (Litman et al., 2017). Of 193 crowdworkers who began the survey, $173(90 \%)$ were eligible for data analysis. Participants were between 20 and 69 years old $(M=37.9, S D=11.4)$ and predominantly male (57\%, one respondent indicated other).

\section{Procedure}

We describe the general procedure here; specific procedures for every group are available online (https://researchbox. org/202). Participants first gave their informed consent and demographics (e.g., age and gender; crowdworkers gave their demographics at the end of the survey). After that, all athletes (i.e., snowboarders, climbers, and gamers) received respective sports-related questions to assess their experience, training routines, and participation in competitions. Participants then read about the BART and answered five comprehension check questions. Depending on the group, they gave on average 4.1 to 4.6 correct answers, with students and snowboarders scoring significantly higher than the other groups, Bonferroni-corrected $p s \leq .046$. They received feedback on any errors regarding these questions. Then, they performed the BART and answered risk-related questions. All participants indicated their GWR (Dohmen et al., 2011); athletes furthermore answered risk-related questions directly addressing their sport. In the end, participants indicated whether they completed the survey carefully ( $98 \%$ reported doing so across all completions), were debriefed, and if applicable, compensated (only students and crowdworkers; students furthermore received a bonus dependent on their BART-performance).

\section{Material}

\section{Risk-Taking Behavior: BART}

Participants performed 20 trials of an online adaption of the BART, programmed in Javascript. In the BART, participants pump up virtual balloons. Each pump increases a balloon's size and value, and continuously, participants have to decide between stopping or going on pumping. While stopping saves the balloon's value, going on further increases its value and its risk to burst, in which case its value is lost to the participant. Each balloon had a predetermined breaking point ranging from 5 to $59(M=32)$ and burst when exceeded. Please note that as in previous research (e.g., Keller \& Gollwitzer, 2017; Sehrig et al., 2021), the number of balloons as well as the breaking point ranges were adjusted and thus deviate from the number of balloons and the three different breaking point ranges proposed in the BART's introduction (Lejuez et al., 2002). We lowered the number of balloons and the breaking points to make the BART shorter and more manageable for participants on mobile devices to perform. Compared to the balloon in the original article that had the highest breaking point range and 30 trials, our parameters meant that optimal behavior (i.e., pumping near to the average breaking point of balloons) would necessitate just onethird of the clicks or touches (in case of mobile devices) that the original parameters would have (i.e., 640 vs. 1920 clicks or touches). Balloons were presented in a fixed order, and each pump increased the current balloon's value by 5 points. These points were presented only after successfully saving a balloon and were then added to a bank account whose balance was permanently displayed at the bottom of the screen. The task was provided in German (students), English (online sample), or both (athletes). Only for students, these points were later translated into money and added to their payoff $(10$ points $=0.01 €)$. Respective sounds accompanied pumps and bursts. Participants were told that there are pumping and burst sounds and asked to adjust their speakers/headphones to hear the sounds. Furthermore, five questions probed the participants' understanding of the task after the instructions to ensure that the participants had read and understood the instructions. We have included this measure because the nature of the administration as an online study forbade that participants may ask an experimenter for any further clarification or information. Also, participants (not only of 
online surveys) are sometimes less attentive than experimenters would like them to be (e.g., Oppenheimer et al., 2009), which makes a further check that instructions for our primary dependent variable are understood correctly all the more important.

Most studies assessing risk-taking behavior in the BART focus on its primary outcome: the average number of pumps across self-stopped balloons (i.e., the adjusted average number of pumps; for why only self-stopped balloons can be used, see Pleskac et al., 2008; Young \& McCoy, 2019) whereas others also looked at the number of burst balloons as an additional variable (e.g., Frey et al., 2017; Keller \& Gollwitzer, 2017; Young \& McCoy, 2019). Although we expect them to be strongly correlated, they both have empirical value because looking only at the adjusted average number of pumps may be misleading in extreme cases. Someone who pumps four times on all 20 balloons before saving them would have the same adjusted average number of pumps as someone who has exceeded the bursting point of all but one balloon saved early by accident after pumping four times. However, in terms of the sum of burst balloons, the two would differ immensely (i.e., 0 vs. 19 burst balloons).

\section{Self-Reported Risk Taking}

General Willingness to Take Risks We asked all participants to rate their willingness to take risks in general on one widely used and predictive item with a 7-point (11-point for the crowdworkers; we transformed their answers to fit the 7-point scale of the other groups) response scale (Arslan et al., 2020; Dohmen et al., 2011). Research has shown this measure to be extremely easy to understand and therefore widely applicable (Arslan et al., 2020). Moreover, it is associated with concepts known to be associated with risk taking (e.g., height, gender; Dohmen et al., 2011) and thus has high external validity. Also, it exhibited similar test-retest reliability and performed as well as longer, more extensive measures of willingness to take risks in predicting the frequency of risk taking regarding real-world risks (Frey et al., 2017).

Sports-Specific Risk Taking We asked athletes to indicate their immediate and delayed regret after taking a risk, whether others would describe their sport-specific style as risky, their regret about having been too passive, and whether they train when feeling physically unwell.

To assess these five variables, climbers, gamers, and snowboarders indicated their agreement with the statements "I get mad at myself when I took a risk while climbing [in a game/while snowboarding]" and "Others would describe my climbing [play/riding] style as risky" on 6-point scales ranging from I totally disagree to I totally agree. After that, they were asked to assess themselves on the following items: "I often get mad at myself afterward that I took a risk while climbing [in a game/while snowboarding]," which was accompanied by examples (e.g., climbing: skipping a hold, gaming: overextending into enemy territory, snowboarding: dangerous overtaking maneuver), "I often get mad at myself that I climbed [played/rode] too passively," and only for climbers and snowboarders, "I still train [ go snowboarding] even if I feel physically unwell," all three to be answered on a 100-point visual analog scale ranging from never to always.

Risk Scenario Moreover, we developed sport-specific scenarios for climbers and snowboarders together with experts (an experienced athlete and a coach). We asked participants to decide how certain they would have to be that a risky action will be successful to take this risk:

[Climbing Scenario] You are climbing a route at your maximum capacity, and there is an opportunity to skip a hold. If you skip the hold, you could either win time and, therefore, save energy for the rest of the route, or lose your way in the route while climbing, lose valuable energy, and - in the worst-case - fail (take a fall). In order to decide if you want to skip the hold: How certain would you have to be that skipping the hold will be successful?

[Snowboarding Scenario] You are riding a jump at your maximum capacity, and there is an opportunity to try a new trick. You could either gain new experience and, therefore, more trust for further tries or fail, and, therefore, you block yourself for the next time, and the worst case is an injury.

In order to decide if you want to perform the trick: How certain would you have to be that you will land the trick?

Answers were recorded on a 7-point visual analog scale ranging from I am certain that it is not successful to 50/50 (midpoint) to I am certain that it is successful, and I wouldn't have to be certain that I land the trick to 50/50 (midpoint) to I would have to be certain that I will land the trick, respectively. Higher scores thus represent a greater need for safety, or to put it differently, less willingness to endure risks.

\section{Results}

First, we tested whether BART-performance correlated with age, gender, and GWR across all five groups (see Table 2). The correlations indicate small but statistically significant relationships between gender and age, pumps, and bursts. On average, female participants were slightly older, indicated 
Table 2 Correlations (with 95\% Confidence Intervals) Between Gender, Age, General Willingness to Take Risks (GWR), and BART-Performance (Adjusted Average Number of Pumps and Number of Bursts)

\begin{tabular}{llllll}
\hline Variable & $(1)$ & $(2)$ & $(3)$ & $(4)$ & $(5)$ \\
\hline (1) Gender & $n=1301$ & $r=.056^{*}[.001, .110]$ & $r=-.129 * * *[-.182,-.075]$ & $r=-.086^{* *}[-.140,-.031]$ & $r=-.117 * * *[-.171,-.063]$ \\
(2) Age & & $n=1304$ & $r=-.049[-.103, .005]$ & $r=-.023[-.078, .031]$ & $r=-.030[-.084, .025]$ \\
(3) GWR & & & $n=1313$ & $r=.098 * * *[.044, .151]$ & $r=.149 * * *[.096, .202]$ \\
(4) BART: Pumps & & & $n=1309$ & $r=.890^{* * *}[.878, .901]$ \\
(5) BART: Bursts & & & & $n=1313$ \\
\hline
\end{tabular}

Note. Values represent parametric Pearson correlation coefficients. Reasons for varying sample sizes were that a) for correlations with Gender, only male (0) and female (1) participants were included in the analyses, b) not all participants indicated their age, and c) four participants had undefined adjusted average number of pumps.

$* p<.05 . * * p<.01 . * * * p<.001$.

to be less willing to take risks, exerted fewer pumps in the BART, and let fewer balloons burst. Furthermore, older participants were less willing to take risks, which also correlated with pumps and bursts. People who reported being more willing to take risks also took more risks in the BART by having a (descriptively) higher adjusted average number of pumps and an average number of bursts. As expected, pumps and bursts were highly but not perfectly correlated. Overall, all variables are correlated in the way we assumed in Table 1 for both stated and revealed risk preferences: Older age is associated with less risk taking, while men are prone to more risk taking. As each association is stronger for the number of bursts than for the adjusted average number of pumps, we will focus on bursts in the subsequent analyses. However, using the number of pumps instead of bursts did not alter the acceptance or rejection of any hypothesis.

Regarding the relationships between risk preferences and highest level of contest participation or (self-reported) skill level, the picture is different for each group. Because both contest participation and (self-reported) skill level are ordinal variables, we will report nonparametric correlation coefficients for correlations with these variables. While there was no relationship among climbers, all Ipls $\leq .076, p \mathrm{~s} \geq$ .152 , there were significant positive relationships between GWR and skill level among both gamers and snowboarders, $\rho=.168, p<.001$, and $\rho=.379, p<.001$, respectively. However, these relationships were not supported by relationships between skill level and BART-performance, all $|\rho| s \leq .118, p s \geq .286$. Furthermore, among gamers, participation in competitions correlated with GWR, $\rho=$ $.106, p=.014$, but not BART-performance, $\rho=.070, p=$ .108. Among snowboarders, GWR and BART-performance correlated with participation in competitions, $\rho=.299, p=$ .006 , and $\rho=.249, p=.022$, respectively.

\section{General Risk Taking}

\section{Self-Reported Risk Taking}

An ANOVA with group as the independent variable and GWR as dependent variable revealed significant differences between the five groups, $F(4,1308)=5.15, p<.001, \eta^{2}=$ .016. Tukey HSD-corrected post-hoc tests reveal significant differences between crowdworkers and students on one side and climbers on the other. Gamers and snowboarders fell in between, being neither significantly more risk seeking than crowdworkers or students nor less risk seeking than climbers (see Fig. 2).

\section{Risk-Taking Behavior}

An ANOVA with group as the independent variable and bursts as the dependent variable revealed significant differences between the five groups, $F(4,1308)=30.96, p<.001$, $\eta^{2}=.086$ (see also Fig. 2).

As a next step, we tested our specific hypothesis that snowboarders and climbers are more risk seeking than gamers, students, or crowdworkers. We created dummy variables for each condition other than climbers and snowboarders. We then ran a hierarchical linear regression model: As the first step, we regressed the adjusted average number of bursts on participants' gender, age, GWR, and their score on the BART comprehension check (as this has differed significantly between groups, see above) which resulted in an overall significant regression model, $F(4,1288)=$ $15.03, p<.001, R^{2}=.045$. As the second step, we added the dummy-coded variables for each of the three comparison groups (i.e., gamers, crowdworkers, and students), which resulted in a significant improvement in explained variance, $F_{\text {change }}(3,1285)=35.61, p<.001, \Delta R^{2}=.073$. Furthermore, all three dummy variables were significant (see Table 3). This indicates that after controlling for gender, age, GWR, and initial understanding of the BART, climbers 
Fig. 2 Self-Reported (GWR) and Elicited (Bursts) Risk

Taking as a Function of Group. Note. Error Bars represent $95 \%$-CIs
Table 3 Model Coefficients of the Linear Regression Testing the Hypothesis that Climbers and Snowboarders are More Risk Seeking in the BART than Crowdworkers, Students, and Gamers.

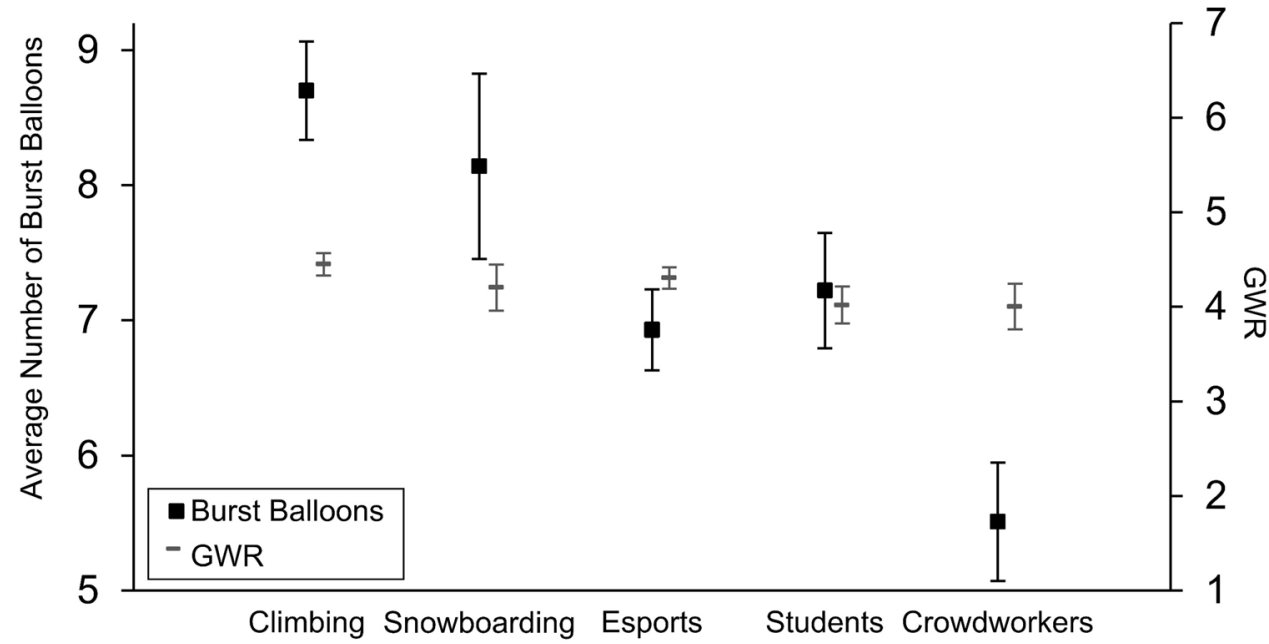

\begin{tabular}{|c|c|c|c|c|}
\hline \multirow[t]{2}{*}{ Variable } & \multicolumn{2}{|l|}{ Step 1} & \multicolumn{2}{|l|}{ Step 2} \\
\hline & $B(S E)$ & $p$ & $B(S E)$ & $p$ \\
\hline Constant & $4.30(0.64)$ & $<.001$ & $6.19(0.67)$ & $<.001$ \\
\hline Gender & $-0.93(0.23)$ & $<.001$ & $-0.97(0.27)$ & $<.001$ \\
\hline Age & $-0.01(0.01)$ & .520 & $-0.01(0.01)$ & .525 \\
\hline GWR & $0.37(0.72)$ & $<.001$ & $0.32(0.07)$ & $<.001$ \\
\hline BART: Comprehension Check & $0.44(0.11)$ & $<.001$ & $0.33(0.11)$ & .002 \\
\hline Crowdworker & & & $-2.64(0.31)$ & $<.001$ \\
\hline University student & & & $-0.86(0.34)$ & .012 \\
\hline Gamer & & & $-1.77(0.23)$ & $<.001$ \\
\hline
\end{tabular}

and snowboarders exhibited more risk taking in the BART than students, crowdworkers, and gamers ${ }^{1}$. When converting the effect sizes from an independent-samples $t$-test into the common-language effect size, there is a $65 \%$ chance that a randomly sampled climber or snowboarder let more balloons burst than a randomly sampled student, crowdworker, or gamer. Means and standard deviations of pumps and bursts in the BART as a function of group are depicted in Table 4.

\section{Sports-Specific Risk Taking}

Next, we analyzed how much variance in sports-specific risk taking can be explained by our background variables, GWR,

\footnotetext{
1 An anonymous reviewer was intrigued by the significant effect of gender in the analyses presented in Table 3. We refrained from discussing this in the main text because gender effects were not the focus of our investigation. Further, we had no hypothesis regarding a difference in gender effects across groups. However, we report and discuss the requested analyses together with a remark by the anonymous reviewer in the supplemental material that can be found in the researchbox repository accompanying this article. In a nutshell, there were no differences between genders in risk taking in the BART for nonathletes. However, there were differences among athletes.
}

Table 4 Means (Standard Deviations) of BART Performance as a Function of Group.

\begin{tabular}{lll}
\hline Group & BART: Bursts & BART: Pumps \\
\hline Climbing & $8.7(3.5)$ & $22.2(7.7)$ \\
Snowboarding & $8.1(3.2)$ & $21.2(8.1)$ \\
Esports & $6.9(3.5)$ & $18.9(8.2)$ \\
Students & $7.2(2.8)$ & $20.5(6.7)$ \\
Crowdworker & $5.5(2.9)$ & $17.1(6.9)$ \\
\hline
\end{tabular}

and BART-performance. Therefore, we ran six regression analyses with all three sports groups combined, using a hierarchical procedure. First, we controlled for group, age, and gender. Then, GWR and the number of bursts in the BART were added as the independent variables of interest in separate, subsequent steps, gauging their explanatory power beyond our control variables.

Table 5 provides an overview of these analyses. GWR correlated with all variables but the need for safety in the risk scenario. In half of the six variables, BART-performance was a significant predictor beyond GWR. Most importantly, the need for safety in the risk scenario was related only to 
Table 5 Linear Hierarchical Regression Models Regressing Sports-Related Risk Taking on a Set of Control Variables (Group, Gender, and Age) and GWR and Bursts in the BART

\begin{tabular}{llll}
\hline Dependent variable & \multicolumn{2}{l}{} & \\
\cline { 2 - 4 } & Control Variables & $G W R$ & BART: Bursts \\
\hline Immediate regret after taking a risk(1-6 scale) & $.070^{* * *}$ & $.019^{* * * *}$ & $.012^{* * *}$ \\
Delayed regret after taking a risk(0-100 scale) & $.091^{* * *}$ & $.009^{* *}$ & $.006^{*}$ \\
Others would describe the style as risky(1-6 scale) & $.086^{* * *}$ & $.107^{* * *}$ & .002 \\
Regret about having been too passive(0-100 scale) & $.019^{* * *}$ & $.008^{* *}$ & .002 \\
Training even when unwell(0-100 scale; without Gamers) & $.040^{* *}$ & $.010^{*}$ & .003 \\
Need for safety in the scenario(1-6 scale; without Gamers) & .014 & $.008^{\dagger}$ & $.052^{* * *}$ \\
\hline
\end{tabular}

Note. Higher values express stronger agreement. $* * * \mathrm{p}<.001,{ }^{*} \mathrm{p}<.010, * \mathrm{p}<.050,{ }^{\dagger} \mathrm{p}<.100$. the number of bursts, meaning that knowing the number of bursts of participants helped explain about $5 \%$ of the variance in their judgment in response to the risk scenario.

\section{Discussion}

We studied differences between extreme sports athletes, esports athletes, and the general public concerning risk appetite. BART-performance distinguished between extreme sports athletes and esports athletes and was meaningfully related to sports-specific risk preferences. Our three distinct control groups (i.e., crowdworkers, students, and gamers) provide evidence for systematic differences in the risk appetite of extreme sports athletes, esport athletes, and the general population. Moreover, our results show that the BART detects these differences and is predictive of sports-specific risk attitudes. Extreme sports athletes were pumping further, risking more balloons in the BART than crowdworkers or students, which reflected a difference in self-reported risk taking (i.e., the reported GWR).

However, esports athletes indicated the second-highest GWR of all groups. Most importantly, success in their sport necessitates risk taking regularly, apparently similar to the experience of extreme sports athletes who also take risks regularly. Still, they were significantly less risk seeking than extreme sports athletes and even students, the latter difference speaking to the importance of incentives as a motivator of risk behavior. This finding further highlights the importance of experiencing physical consequences in one's sport regarding elicited but not self-reported risk-taking behavior. To put it differently, while gamers thought themselves to be relatively risk seeking, they behaved more risk averse in a behavioral risk measure.

Regarding extreme sports athletes, our results reveal that they do not necessarily see themselves as more risk seeking than other groups in their self-reported risk taking. However, this is misguiding as the assessment of risk-taking behavior through the BART revealed essential differences between groups. Extreme sports athletes show more extreme values in the BART, a context-independent measure of risk taking, leading them to surpass an incentivized control group of university students and a sample of gamers comprising primarily younger men who are usually considered to be very risk seeking. As a potential caveat, one should note that we did not assess whether university students, gamers, or crowdworkers also engage in extreme sports. However, while it is possible that some subjects in the student, gamer, or crowdworker samples were also engaging in risky sports, this would have only attenuated the difference in risk taking we observed between extreme and non-extreme sports athletes. In turn, the results presented here likely underestimate the true differences that exist between extreme sports athletes and control samples with respect to the willingness to take risks.

Moreover, BART-performance was correlated with affective consequences of risk taking (i.e., immediate and delayed regret) and, most importantly, with the stated need for safety to perform a risky behavior that may entail a significant competitive advantage but also incurs a significant chance of injury. These relationships highlight the BART's practical value, accounting for variance in sports-related risk taking and potentially translating into variance in risk of injury.

However, except for the highest level of contest participation among snowboarders, the BART did not correlate with skill or contest participation levels. A tentative explanation could be based on the observation that, in contrast to the BART-performance, self-reported risk taking correlated with skill and contest participation levels across gamers and snowboarders. Accordingly, a) risk taking does not vary across skill levels while b) self-perceptions do (cf. Vaughan et al., 2018). This pattern could reflect the ongoing self-selection into competitions and the feedback they receive about their skill level. The latter would also be in line with the relationship between the self-report and how others would describe their style. 


\section{Conclusion}

Behavioral data from 1313 participants across five different groups suggest that the potential of physically adverse events inherent in extreme sports is associated with differences in risk taking between extreme sports athletes (i.e., climbers and snowboarders), esports athletes, and non-athletes, even when some non-athletes were incentivized to behave in a risk-seeking manner. Interestingly, the BART was also a strong predictor of sports-specific risk taking and its affective consequences. The results suggest that extreme sports athletes' increased risk taking is not necessarily reflected in their self-reports of willingness to take risks. Our work validates using the BART as an individual difference measure in sports. It has significant implications beyond sports in all domains that necessitate decision-making that might involve physical harm.

Funding Information Open Access funding enabled and organized by Projekt DEAL. Our work was funded by Grant 441551024 "Updating Risk" from the Deutsche Forschungsgemeinschaft (DFG, [German Research Foundation]) awarded to the first author. We thank Marc Aeberhard, Florian Heymann, and Nils Jakubzig for their help in data collection and survey creation.

Data Availability The datasets generated during and/or analyzed during the current study are available in the researchbox repository, https:// researchbox.org/202.

\section{Declarations}

Consent to Participate Informed consent was obtained from all individual participants included in the study.

Ethics Approval All procedures performed in studies involving human participants were in accordance with the ethical guidelines of the Institutional Review Board of the University of Konstanz (Ethikkommission), Konstanz, Germany, and with the 1964 Helsinki declaration and its later amendments or comparable ethical standards.

Conflict of Interest On behalf of all authors, the corresponding author states that there is no conflict of interest.

Open Access This article is licensed under a Creative Commons Attribution 4.0 International License, which permits use, sharing, adaptation, distribution and reproduction in any medium or format, as long as you give appropriate credit to the original author(s) and the source, provide a link to the Creative Commons licence, and indicate if changes were made. The images or other third party material in this article are included in the article's Creative Commons licence, unless indicated otherwise in a credit line to the material. If material is not included in the article's Creative Commons licence and your intended use is not permitted by statutory regulation or exceeds the permitted use, you will need to obtain permission directly from the copyright holder. To view a copy of this licence, visit http://creativecommons.org/licenses/by/4.0/.

\section{References}

Aklin, W. M., Lejuez, C. W., Zvolensky, M. J., Kahler, C. W., \& Gwadz, M. (2005). Evaluation of behavioral measures of risk taking propensity with inner city adolescents. Behavior Research and Therapy, 43(2), 215-228. https://doi.org/10.1016/j.brat.2003. 12.007

Allman, T. L., Mittelstaedt, R. D., Martin, B., \& Goldenberg, M. (2009). Exploring the motivations of BASE jumpers: Extreme sports enthusiasts. Journal of Sport \& Tourism, 14(4), 229-247. https://doi.org/10.1080/14775080903453740

Arslan, R. C., Brümmer, M., Dohmen, T., Drewelies, J., Hertwig, R., \& Wagner, G. G. (2020). How people know their risk preference. Scientific Reports, 10, Article 15365. https://doi.org/10.1038/ s41598-020-72077-5

Banducci, A. N., Felton, J. W., Dahne, J., Ninnemann, A., \& Lejuez, C. W. (2015). Maternal risk taking on the Balloon Analogue Risk Task as a prospective predictor of youth alcohol use escalation. Addictive Behaviors, 49, 40-45. https://doi.org/10. 1016/j.addbeh.2015.05.011

Baretta, D., Greco, A., \& Steca, P. (2017). Understanding performance in risky sport: The role of self-efficacy beliefs and sensation seeking in competitive freediving. Personality and Individual Differences, 117, 161-165. https://doi.org/10.1016/j. paid.2017.06.006

Barlow, M., Woodman, T., \& Hardy, L. (2013). Great expectations: Different high-risk activities satisfy different motives. Journal of Personality and Social Psychology, 105(3), 458-475. https://doi. org/10.1037/a0033542

Brañas-Garza, P., Estepa-Mohedano, L., Jorrat, D., Orozco, V., \& Rascón-Ramírez, E. (2021). To pay or not to pay: Measuring risk preferences in lab and field. Judgment and Decision Making, 16(5), 1290-1313.

Brymer, E. (2010). Risk taking in extreme sports: A phenomenological perspective. Annals of Leisure Research, 13(1-2), 218-238. https://doi.org/10.1080/11745398.2010.9686845

Brymer, E., \& Mackenzie, S. H. (2017). Psychology and the extreme sport experience. In F. Feletti (Ed.), Extreme sports medicine (pp. 3-13). Springer. https://doi.org/10.1007/978-3-319-28265-7_1

Buelow, M. T., Okdie, B. M., \& Cooper, A. B. (2015). The influence of video games on executive functions in college students. Computers in Human Behavior, 45, 228-234. https://doi.org/10.1016/j. chb.2014.12.029

Camerer, C. F., \& Hogarth, R. M. (1999). The effects of financial incentives in experiments: A review and capital-labor-production framework. Journal of Risk and Uncertainty, 19, 7-42. https://doi. org/10.1023/A:1007850605129

Carver, C. S., \& Scheier, M. F. (1990). Origins and functions of positive and negative affect: A control-process view. Psychological Review, 97(1), 19-35. https://doi.org/10.1037/0033-295X.97.1.19

Charness, G., \& Gneezy, U. (2012). Strong evidence for gender differences in risk taking. Journal of Economic Behavior \& Organization, 83(1), 50-58. https://doi.org/10.1016/j.jebo.2011.06.007

Cohen, R., Baluch, B., \& Duffy, L. J. (2018). Defining extreme sport: Conceptions and misconceptions. Frontiers in Psychology, 9, Article 1974. https://doi.org/10.3389/fpsyg.2018.01974

Crust, L. (2020) Personality and mountaineering: A critical review and directions for future research. Personality and Individual Differences, 163, Article 110073. https://doi.org/10.1016/j.paid.2020. 110073 
Dohmen, T., Falk, A., Huffman, D., Sunde, U., Schupp, J., \& Wagner, G. (2011). Individual risk attitudes: Measurement, determinants, and behavioral consequences. Journal of the European Economic Association, 9(3), 522-550. https://doi.org/10.1111/j.1542-4774. 2011.01015. $\mathrm{x}$

Drummond, A., Sauer, J. D., Ferguson, C. J., Cannon, P. R., \& Hall, L. C. (2021). Violent and non-violent virtual reality video games: Influences on affect, aggressive cognition, and aggressive behavior. Two pre-registered experiments. Journal of Experimental Social Psychology, 95, Article 104119. https://doi.org/10.1016/j. jesp.2021.104119

Faul, F., Erdfelder, E., Lang, A.-G., \& Buchner, A. (2007). G*Power 3: A flexible statistical power analysis program for the social, behavioral, and biomedical sciences. Behavior Research Methods, 39(2), 175-191. https://doi.org/10.3758/bf03193146

Fischer, P., Kubitzki, J., Guter, S., \& Frey, D. (2007). Virtual driving and risk taking: Do racing games increase risk-taking cognitions, affect, and behaviors? Journal of Experimental Psychology: Applied, 13(1), 22-31. https://doi.org/10.1037/1076-898X.13.1.22

Franques, P., Auriacombe, M., Piquemal, E., Verger, M., BrisseauGimenez, S., Grabot, D., \& Tignol, J. (2003). Sensation seeking as a common factor in opioid dependent subjects and high risk sport practicing subjects. A cross sectional study. Drug and Alcohol Dependence, 69, 121-126. https://doi.org/10.1016/S03768716(02)00309-5

Frey, R., Pedroni, A., Mata, R., Rieskamp, J., \& Hertwig, R. (2017). Risk preference shares the psychometric structure of major psychological traits. Science Advances, 3(10), Article e1701381. https://doi.org/10.1126/sciadv.1701381

Gamble, T., \& Walker, I. (2016). Wearing a bicycle helmet can increase risk taking and sensation seeking in adults. Psychological Science, 27(2), 289-294. https://doi.org/10.1177/0956797615620784

Gough, C. (2021). Esports market revenue worldwide from 2019 to 2024. Statista. https://www.statista.com/statistics/490522/globalesports-market-revenue/

Hanoch, Y., Johnson, J. G., \& Wilke, A. (2006). Domain specificity in experimental measures and participant recruitment: An application to risk-taking behavior. Psychological Science, 17(4), 300304. https://doi.org/10.1111/j.1467-9280.2006.01702.x

Hilgard, J., Engelhardt, C. R., Rouder, J. N., Segert, I. L., \& Bartholow, B. D. (2019). Null effects of game violence, game difficulty, and 2D:4D digit ration on aggressive behavior. Psychological Science, 30, 606-616. https://doi.org/10.1177/0956797619829688

Hopko, D. R., Lejuez, C. W., Daughters, S. B., Aklin, W. M., Osborne, A., Simmons, B. L., \& Strong, D. R. (2006). Construct validity of the Balloon Analogue Risk Task (BART); Relationship with MDMA use by inner-city drug users in residential treatment. Journal of Psychopathology and Behavioral Assessment, 28(2), 95-101. https://doi.org/10.1007/s10862-006-7487-5

Hull, J. G., Brunelle, T. J., Prescott, A. T., \& Sargent, J. D. (2014). A longitudinal study of risk-glorifying video games and behavioral deviance. Journal of Personality and Social Psychology, 107(2), 300-325. https://doi.org/10.1037/a0036058

Hunt, M. K., Hopko, D. R., Bare, R., Lejuez, C. W., \& Robinson, E. V. (2005). Construct validity of the Balloon Analog Risk Task (BART): Associations with psychopathy and impulsivitiy. Assessment, 12(4), 416-428. https://doi.org/10.1177/2F1073191105278 740

Keller, L., Bieleke, M., Koppe, K.-M., \& Gollwitzer, P. M. (2021). Overclaiming is not related to dark triad personality traits or stated and revealed risk preferencs. PLOS ONE, 16(8), e0255207. https:// doi.org/10.1371/journal.pone.0255207

Keller, L., \& Gollwitzer, P. M. (2017). Mindsets affect risk perceptions and risk-taking behavior - Illusory optimism and the BART. Social Psychology, 48(3), 135-147. https://doi.org/10.1027/18649335/a000304

Lauriola, M., Panino, A., Levin, I. P., \& Lejuez, C. W. (2014). Individual differences in risky decision making: A meta-analysis of sensation seeking and impulsivity with the Balloon Analogue Risk Task. Journal of Behavioral Decision Making, 27, 20-36. https:// doi.org/10.1002/bdm.1784

Lejuez, C. W., Aklin, W. M., Zvolensky, M. J., \& Pedulla, C. M. (2003). Evaluation of the Balloon Analogue Risk Task (BART) as a predictor of adolescent real-world risk-taking behaviours. Journal of Adolescence, 26(4), 475-479. https://doi.org/10.1016/ S0140-1971(03)00036-8

Lejuez, C. W., Read, J. P., Kahler, C. W., Richards, J. B., Ramsey, S. E., Stuart, G. L., Strong, D. R., \& Brown, R. A. (2002). Evaluation of a behavioral measure of risk taking: The Balloon Analogue Risk Task (BART). Journal of Experimental Psychology: Applied, 8(2), 75-84. https://doi.org/10.1037/1076-898X.8.2.75

Litman, L., Robinson, J., \& Abberbock, T. (2017). TurkPrime.com: A versatile crowdsourcing data acquisition platform for the behavioral sciences. Behavior Research Methods, 49(2), 433-442. https:// doi.org/10.3758/s13428-016-0727-z

Oppenheimer, D. M., Meyvis, T., \& Davidenko, N. (2009). Instructional manipulation checks: Detecting satisficing to increase statistical power. Journal of Experimental Social Psychology, 45(4), 867-872. https://doi.org/10.1016/j.jesp.2009.03.009

Pedraza-Ramirez, I., Musculus, L., Raab, M., \& Laborde, S. (2020). Setting the scientific stage for esports psychology: A systematic review. International Review of Sport and Exercise Psychology, 13(1), 319-352. https://doi.org/10.1080/1750984X.2020.1723122

Pleskac, T., Wallsten, T. S., Wang, P., \& Lejuez, C. W. (2008). Development of an automatic response mode to improve the clinical utility of sequential risk-taking tasks. Experimental and Clinical Psychopharmacology, 16(6), 555-567. https://doi.org/10.1037/ a0014245

Rolison, J. J., Hanoch, Y., \& Wood, S. (2012). Risky decision making in younger and older adults: The role of learning. Psychology and Aging, 27(1), 129-140. https://doi.org/10.1037/a0024689

Schneider, D., \& Greenberg, M. R. (1992). Choice of exercise: A predictor of behavioral risks? Research Quarterly for Exercise and Sport, 63(3), 231-237. https://doi.org/10.1080/02701367.1992. 10608738

Sehrig, S., Odenwald, M., \& Rockstroh, B. (2021). Feedback-Related brain potentials indicate the influence of craving on decisionmaking in patients with alcohol use disorder: An experimental study. European Addiction Research, 27, 216-226. https://doi.org/ $10.1159 / 000511417$

Steinbrink, K. M., Berger, E. S. C., \& Kuckertz, A. (2020). Top athletes' psychological characteristics and their potential for entrepreneurship. International Entrepreneurship and Management Journal, 16, 859-878. https://doi.org/10.1007/s11365-019-00612-6

Steiner, M., \& Frey, R. (2021). Representative design in psychological assessment: A case study using the Balloon Analogue Risk Task (BART). Journal of Experimental Psychology: General. https:// doi.org/10.1037/xge0001036

Stollberg, E., \& Lange, K. W. (2020). The effects of video racing games on risk-taking in consideration of the game experience. PLOS 
ONE, 15(10), Article e0240367. https://doi.org/10.1371/journal. pone. 0240367

Vaughan, R., Laborde, S., \& McConville, C. (2018). The effect of athletic expertise and trait emotional intelligence on decision-making. European Journal of Sport Science, 19(2), 225-233. https:// doi.org/10.1080/17461391.2018.1510037

Wetherill, R. R., \& Fromme, K. (2007). Alcohol use, sexual activity, and perceived risk in high school athletes and non-athletes. Journal of Adolescent Health, 41(3), 294-301. https://doi.org/10. 1016/j.jadohealth.2007.04.019

Young, M. E., \& McCoy, A. W. (2019). Variations on the Balloon Analogue Risk Task: A censored regression analysis. Behavior
Research Methods, 51, 2509-2521. https://doi.org/10.3758/ s13428-018-1094-8

Zeelenberg, M. (1999). Anticipated regret, expected feedback and behavioral decision making. Journal of Behavioral Decision Making, 12(2), 93-106. https://doi.org/10.1002/(SICI)10990771(199906)12:2\%3C93::AID-BDM311\%3E3.0.CO;2-S

Publisher's Note Springer Nature remains neutral with regard to jurisdictional claims in published maps and institutional affiliations. 